\title{
REDESIGN AND THERMAL ANALYSIS OF TRANSFER MOLD TOOL
}

\author{
Sateesh Mudalagi ${ }^{1}$, Mahantesh Tanodi $^{2}$, S.B.Yapalaparvi ${ }^{3}$ \\ ${ }^{1}$ Design Engineer, KDDL Ltd EIGEN UNIT Bangalore, Karnataka State, India \\ ${ }^{2}$ Lecturer, ${ }^{3}$ HOD, Department of Mechanical Engineering, Hirasugar Institute of Technology Nidasoshi, Karnataka, \\ India
}

\begin{abstract}
This paper presents the redesign of a transfer molded tool for producing stacked molded component for power tools and performing thermal analysis for the mould to access on the effect of thermal expansion and thermal stress in the mold. Selected transfer tool material is cold work tool D2 steel. The technique, theory, methods as well as consideration needed in redesigning of transfer molded tool are presented. The model for thermal expansion and thermal stresses due to working of tool at a high temperature is developed and solved using commercial finite element analysis software called ANSYS WORKBENCH. From the analysis obtain the thermal effect on parts of the tool. Provide optimum clearance between sliding part of the tool. Vary the dimension of the plunger and cavity back plate hole as per analysis result In order to operate the tool precisely.
\end{abstract}

Keywords: Transfer molded tool, Redesign, Thermal analysis. $* * *$

\section{INTRODUCTION}

Transfer mold used as a compression mold [1] producing thermoset [2] precision components. The mold expose during to temperature of $250^{\circ} \mathrm{C}$ during casting. Transfer mold is used to produce molded stack component for the power tools. Where use material is Bulk-molding compound (BMC) [3] to fill the gap between shaft and laminates. The melting temperature of the BMC is $2500 \mathrm{c}$. For that reason the transfer mold has to heat beyond 2500c with the help of heat cartridge. The transfer molded tool is not working properly it is making abnormal sound during opening and closing of top and bottom half of the tool. It is due to the parts of the tool are expanding at working temperature 2500c. Critical parts of the tool like bush, plunger, pillar and bush and ejection pin will get expand at that temperature and vary their dimension. Due to this reason it is necessary to provide the optimum clearance between the above mentioned critical parts and also reduce the thermal stresses induced in these parts in order to work the tool properly at 2500c. The main objective is to analyze the optimum clearance between sliding parts of the transfer molded tool due to thermal expansion and effect of thermal residual stresses induced in the part of the tool.

\section{HEADING 2}

\subsection{Couple Field analysis}

A coupled-field analysis is an analysis that takes into account the interaction (coupling) between two or more disciplines (fields) of engineering. Considered couple field is structural-thermal field analysis. Sequential couple field method is used to obtain the analysis results.

\subsection{Material Properties and Geometry}

Geometry of the tool is selected for thermal analysis is as shown below Fig.2.1. This assembly of the tool mainly consists of plunger, cavity plate cavity back plate and guide bush and pillar.

Table-1: Material properties

\begin{tabular}{|l|c|c|}
\hline \multirow{2}{*}{ Properties } & \multicolumn{2}{|c|}{ Materials } \\
\cline { 2 - 3 } & $\begin{array}{c}\text { Cold work } \\
\text { tool steel } \\
\text { (D2 material) }\end{array}$ & Mild Steel \\
\hline Density (Kg/m3 ) & 7600 & 7850 \\
\hline $\begin{array}{l}\text { Coeff. Of thermal } \\
\text { expansion (C^-1) }\end{array}$ & $1.2 \mathrm{e}-5$ & $1.13 \mathrm{e}-5$ \\
\hline $\begin{array}{l}\text { Reference } \\
\text { Temperature (0C) }\end{array}$ & 30 & 30 \\
\hline $\begin{array}{l}\text { Young's Modulus } \\
\text { (Pa) }\end{array}$ & $1.8 \mathrm{e} 11$ & $2.1 \mathrm{e} 11$ \\
\hline Poisson ratio & 0.3 & 0.3 \\
\hline $\begin{array}{l}\text { Thermal } \\
\text { Conductivity (W/mc) }\end{array}$ & 23 & 46 \\
\hline
\end{tabular}

Fig.2.2 shows the meshing of tool, considered element type was tetrahedral element.

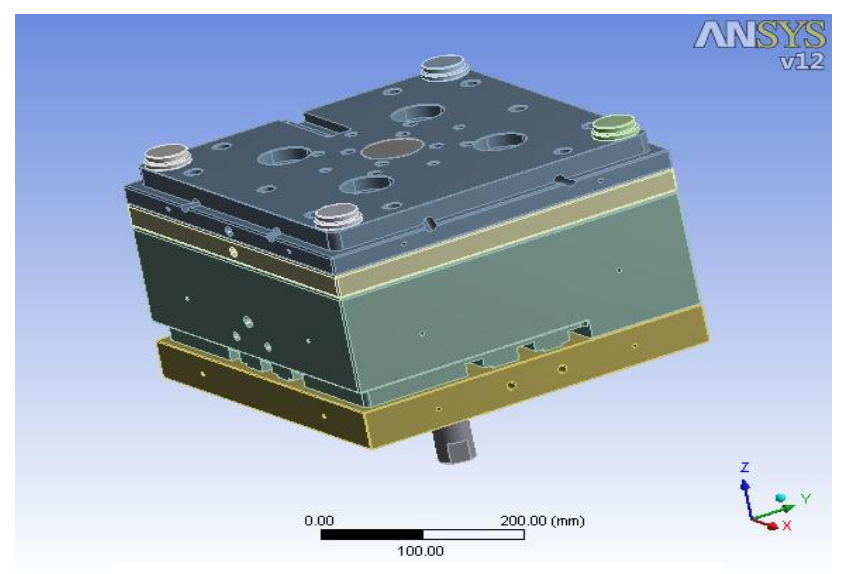

Fig-1:Tool geometry 


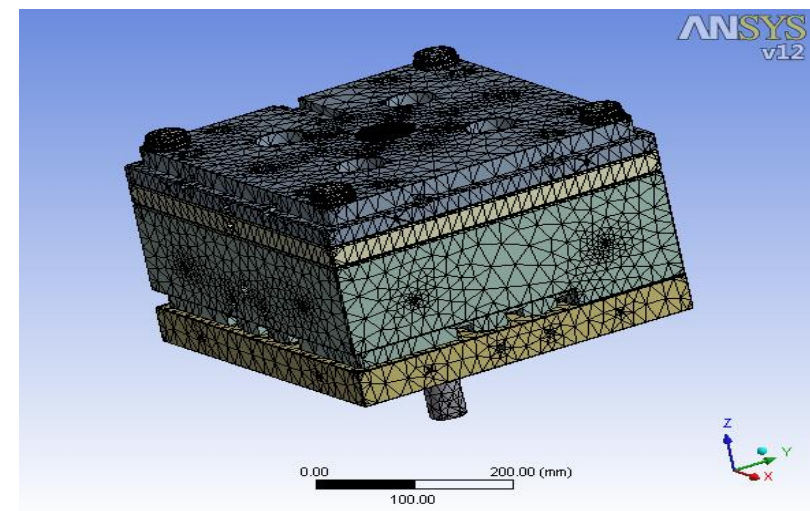

Fig-2:Tool geometry mesh

SOLID 87 is well suited to model irregular meshes (such as produced from various CAD/CAM systems). The element has one degree of freedom, temperature, at each node. The element is applicable to a three-dimensional, steady-state or transient thermal analysis. As shown in Fig 2.2

Tool maintains steady state temperature of $2500 \mathrm{c}$, which is applied to the whole tool. Natural convection is taking place from the out surface of the tool which is of $25 \mathrm{~W} / \mathrm{mm} 2{ }^{\circ} \mathrm{C}$ .Tool is surrounded by heat resistance plate, made from Hylum material. There is no transfer of heat at the bottom of the cavity back plate due to presence of heat resistance plate.

\section{RESULTS AND DISCUSSION}

\subsection{For Plunger}

Plunger is mainly surrounded by two components. One is cavity back plate and other one is plunger_cv_holder (bush). Plunger is sliding within bush, to push the molten plastic in to the cavity through runner and gate. From the thermal analysis it is found that the plunger is getting stuck in to the cavity back plate hole of diameter $54 \mathrm{~mm}$ as shown in Fig 3.1. It is due to the plunger is working at a temperature of 2500c and material used for it is D2 material but for the cavity back plate is of mild steel. Hence the presence of different materials and thermally constrained at the bottom of cavity back plate. Cavity back plate hole expand less compare to plunger. Hence cavity back plate hole will not allow plunger to expand freely. Fig 3.1 \& Fig 3.2 represents the deformation of plunger at 2500c along length and diameter respectively.

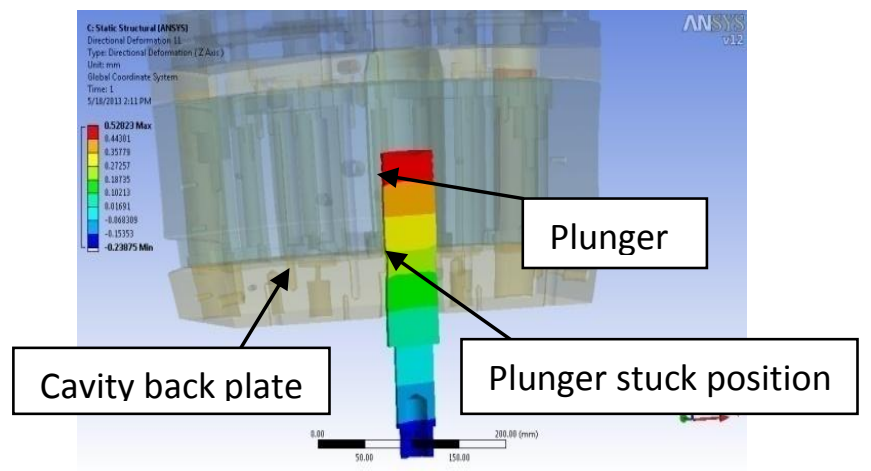

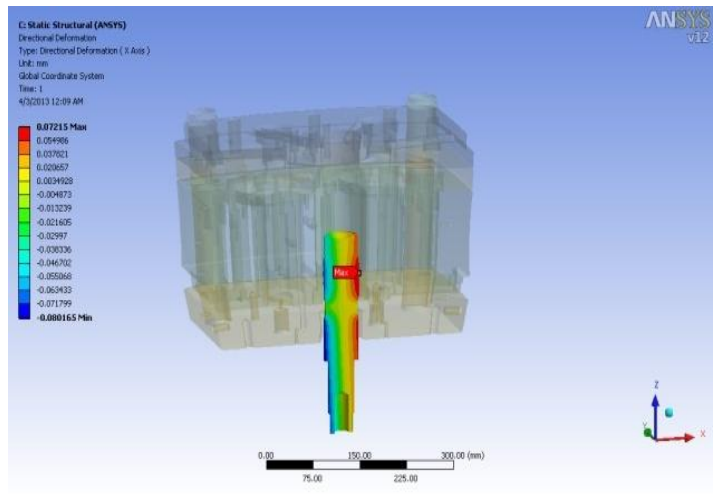

Fig-4:. Deformation along diameter of plunger

Fallowing graphs represents the problem encounter in the plunger movement.

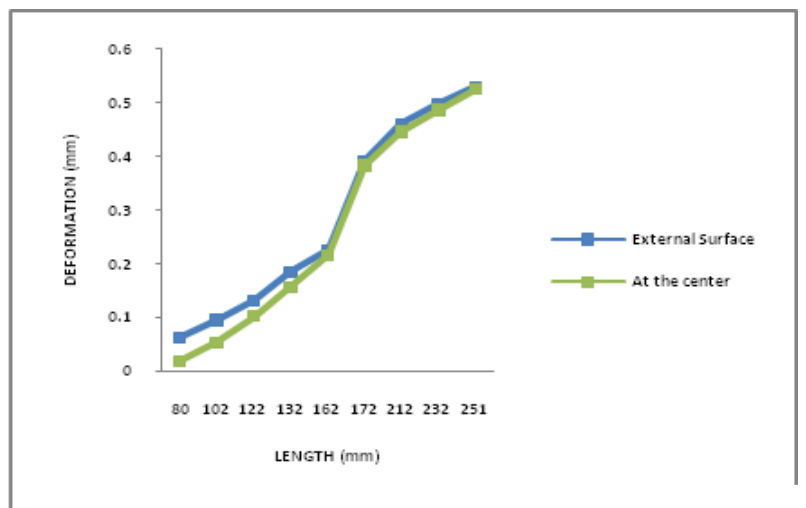

Fig-5:Deformation of plunger along its length

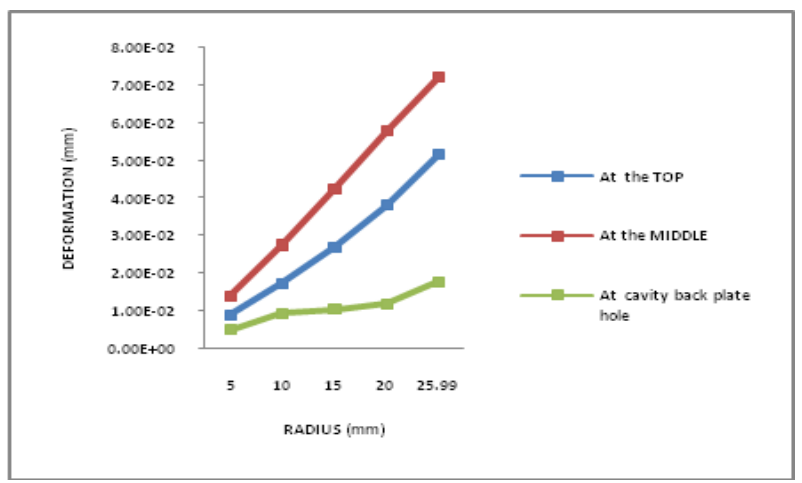

Fig-6:Deformation of plunger along its diameter

Fig 3.3 and Fig 3.4 represents the deformation of plunger along its length and diameter respectively for the cavity back plate hole diameter of $54 \mathrm{~mm}$. Corresponding stress along the length and diameter of plunger as shown in Fig 3.5 corresponding graphs as shown in Fig 3.7 \& Fig 3.8 respectively. Figures represent the effect of $54 \mathrm{~mm}$ diameter of cavity back plate hole on plunger movement.

Fig-3: Deformation along length of plunger 


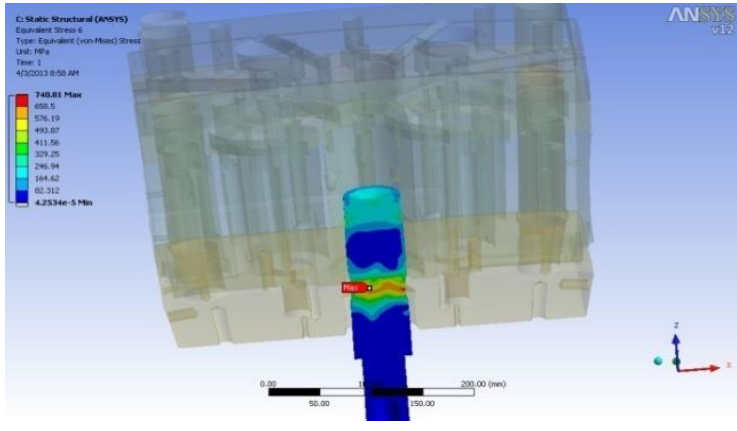

Fig-7: Stress in the plunger

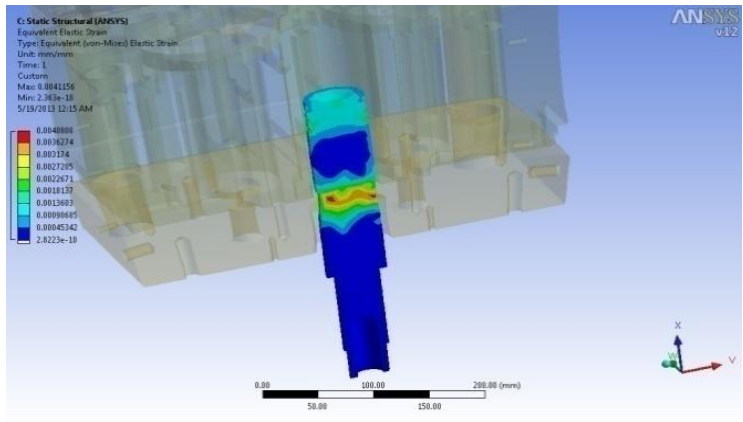

Fig-8: Strain in the plunger

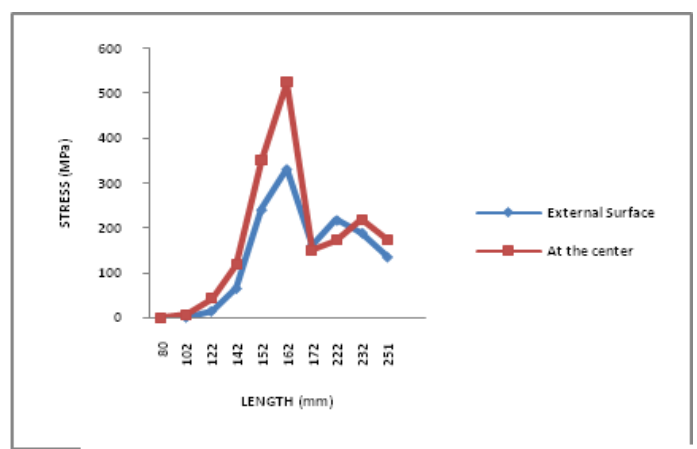

Fig-9: Stress along length of plunger

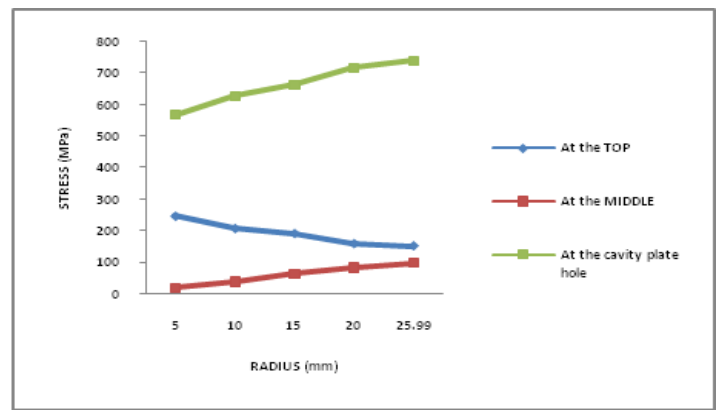

Fig-10:Stress along diameter of plunger

Strain along the length and diameter of plunger as shown in Fig 4.6 and corresponding graph as shown in Fig 3.9 \& Fig 3.10 respectively.

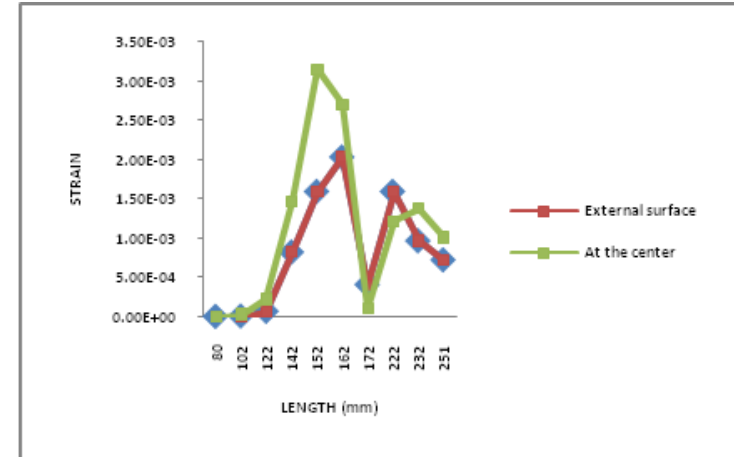

Fig-11: Strain along length of plunger

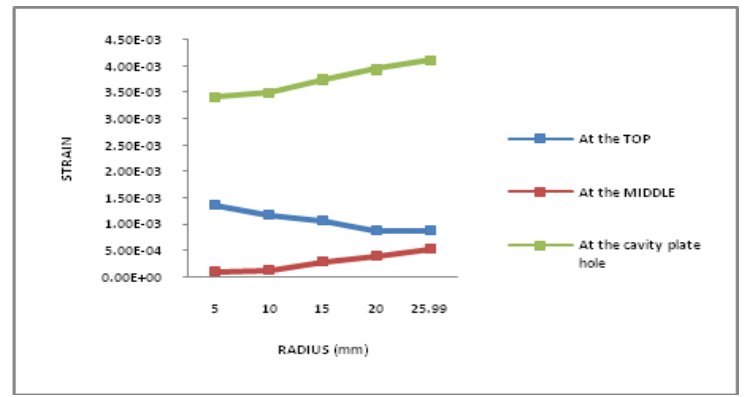

Fig-11: Strain along diameter of plunger

From the above results it is clear that at the length 122 to $172 \mathrm{~mm}$ of plunger having more stress and strain due to non-uniform deformation of plunger within $54 \mathrm{~mm}$ diameter of cavity back plate.

In order to avoid these stress and strain, increase the diameter of the cavity back plate hole up to $56 \mathrm{~mm}$. corresponding deformation of plunger along its length and diameter for $56 \mathrm{~mm}$ hole diameter compare with $54 \mathrm{~mm}$ diameter of cavity back plate hole. Fig 3.11 and Fig 3.12 showed the deformation of plunger along its length and diameter respectively. Corresponding graphs are Fig (3.13, 3.14 ) and Fig 3.15 respectively.

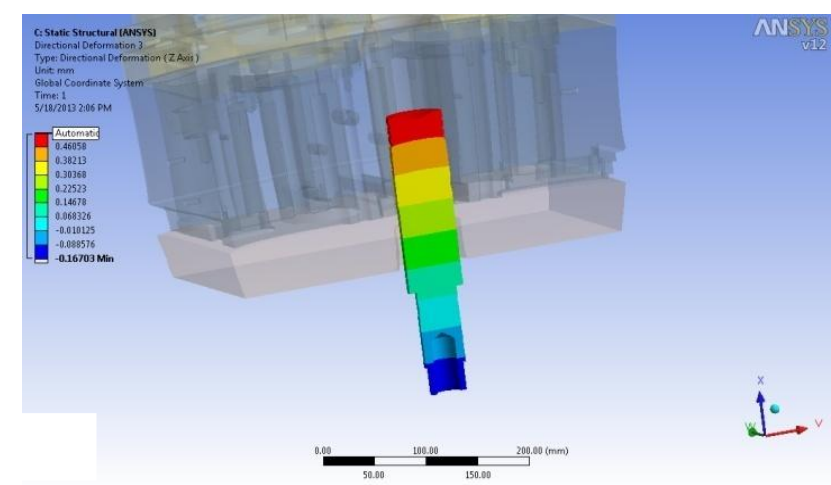

Fig-12:Deformation along length of plunger 


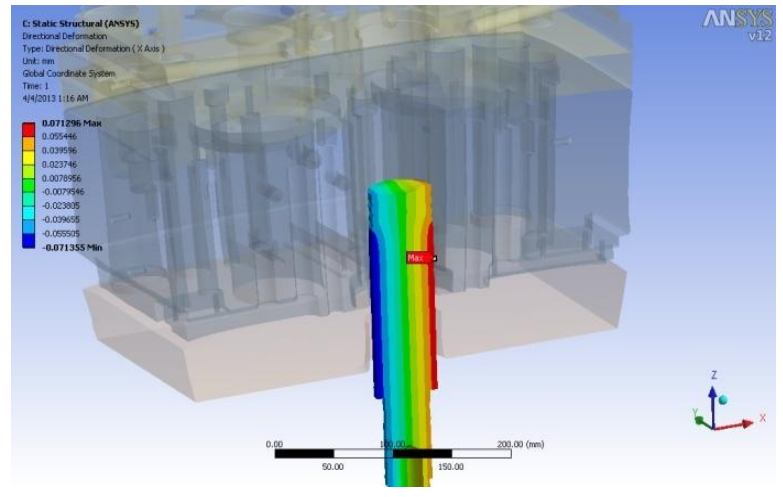

Fig-13:Deformation along diameter of plunger

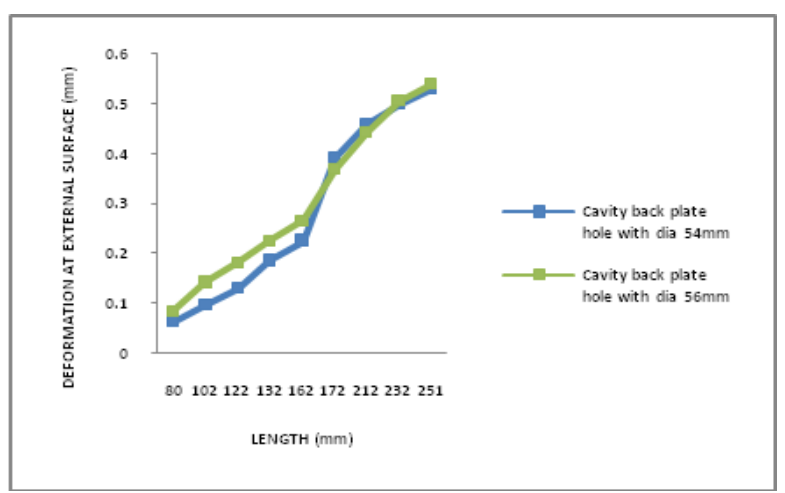

Fig-14:deformation along length at ext. surface of plunger

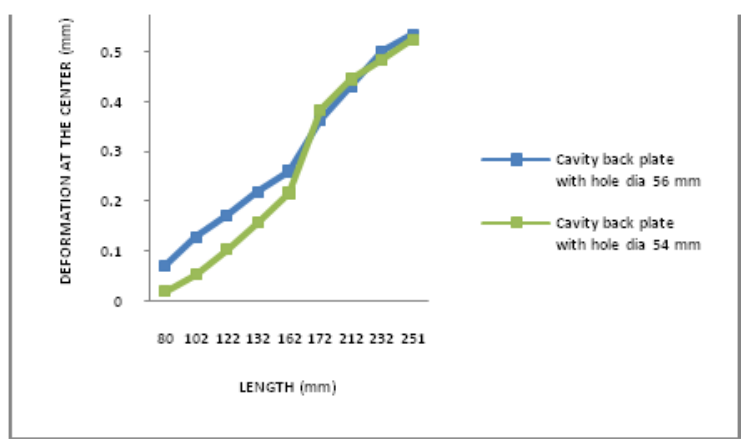

Fig. 3.14 deformation along length at the center of plunger

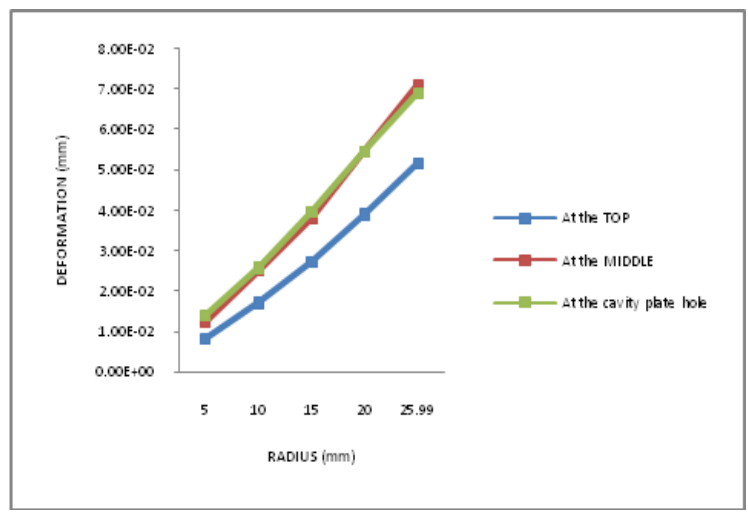

Fig. 3.15 deformation along diameter of plunger
Stresses at $56 \mathrm{~mm}$ hole diameter for plunger along its length and diameter as shown in Fig 3.16 and corresponding graphs for stresses along its length and diameter as shown in Fig $(3.18,3.20)$ and Fig 3.22 respectively. Strain at $56 \mathrm{~mm}$ diameter hole for plunger along its length and along its diameter as shown in Fig 3.17 and corresponding graphs for stresses along its length and diameter as shown in Fig (3.19, 3.21) and Fig. 3.23 respectively.

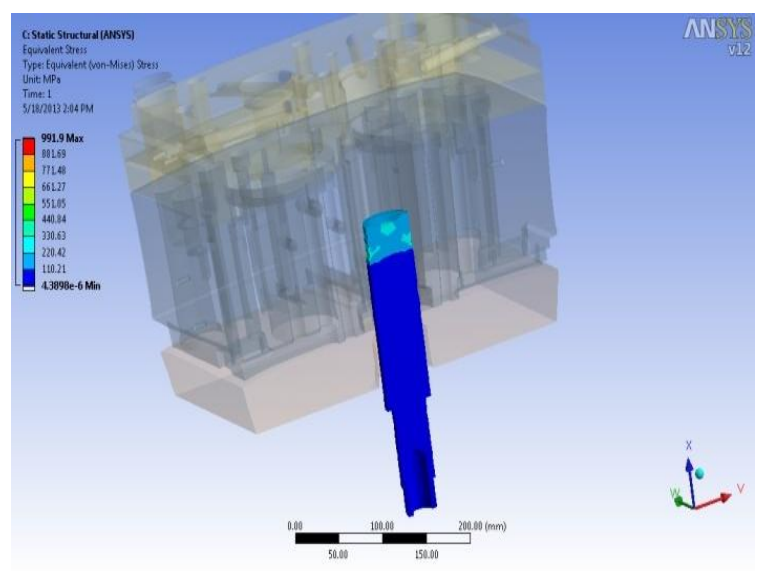

Fig. 3.16 Stress in the plunger

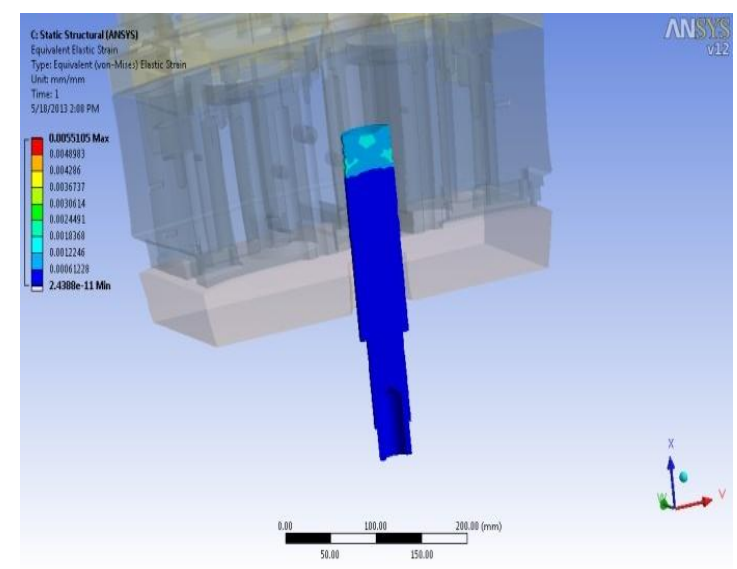

Fig 3.17 Strain in the plunger

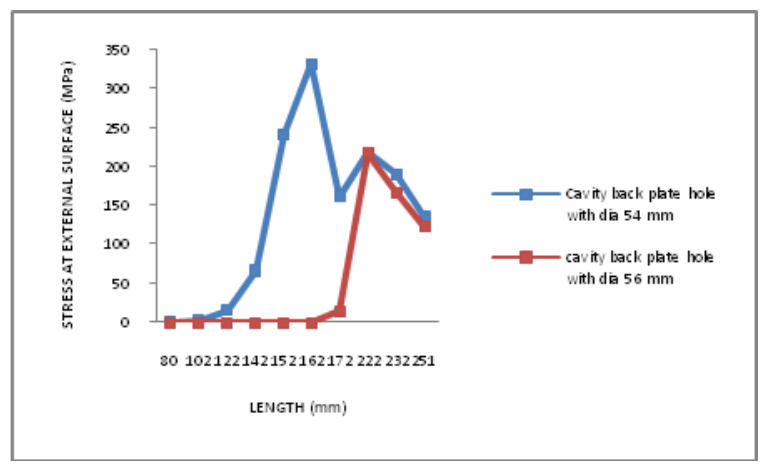

Fig.3.18 stress along length at ext. surface of plunger 


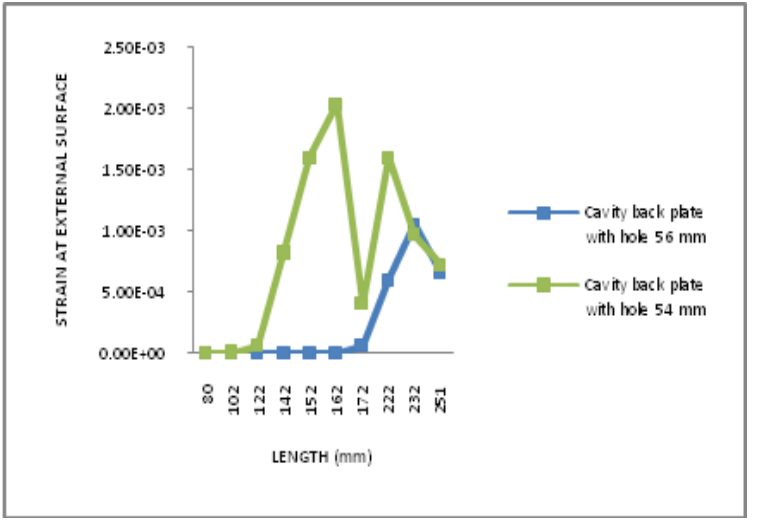

Fig. 3.19 strain along length at ext. surface of plunger

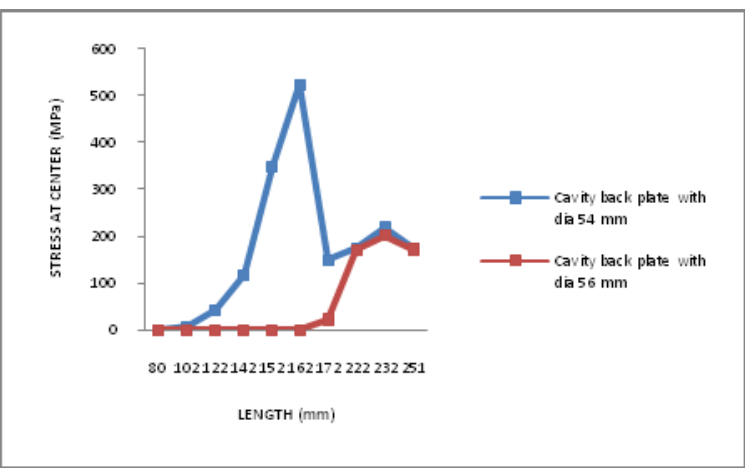

Fig. 3.20 stress along length at the center of plunger

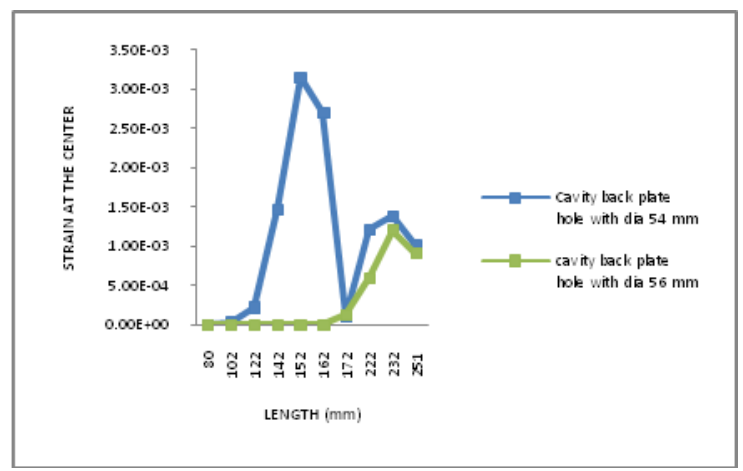

Fig. 3.21 strain along length at the center of plunger

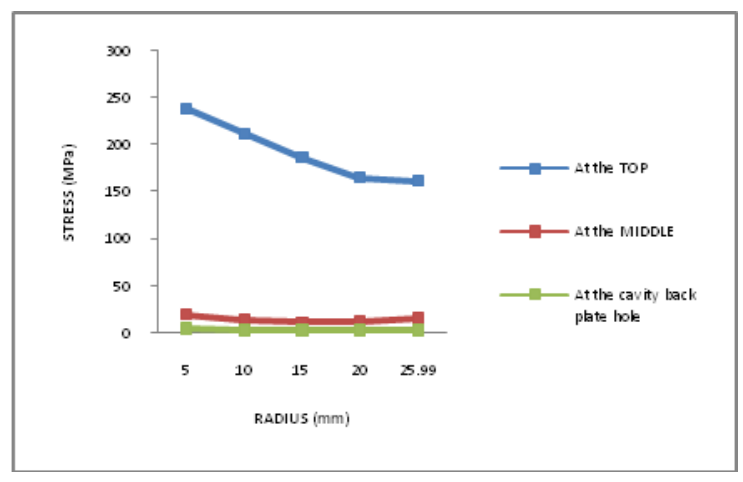

Fig. 3.22 stress along diameter of plunger

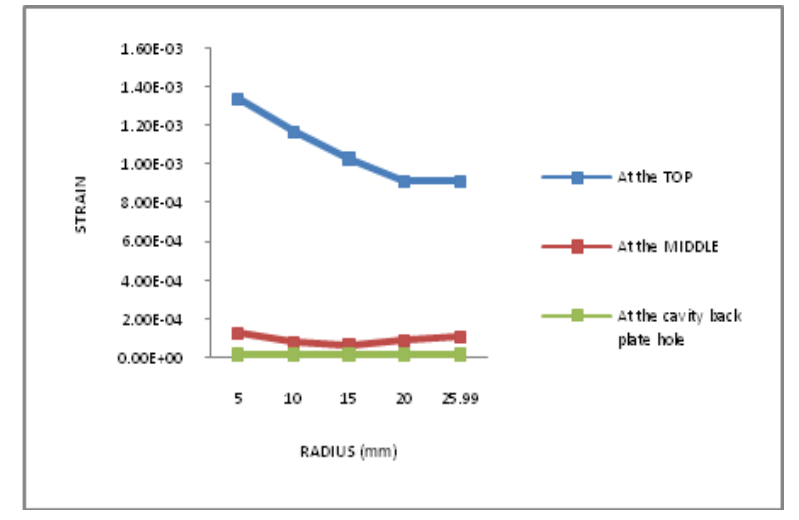

Fig. 3.23 strain along diameter of plunger

\subsection{FOR BUSH}

Bush is part of the tool help to guide the plunger to slide properly and deformation of bush along its length and thickness at $250^{\circ} \mathrm{c}$ as shown in Fig 3.24 and Fig 3.25 respectively. Corresponding graphs for deformation along length and thickness of the bush are shown in the Fig 3.26 and Fig 3.27.

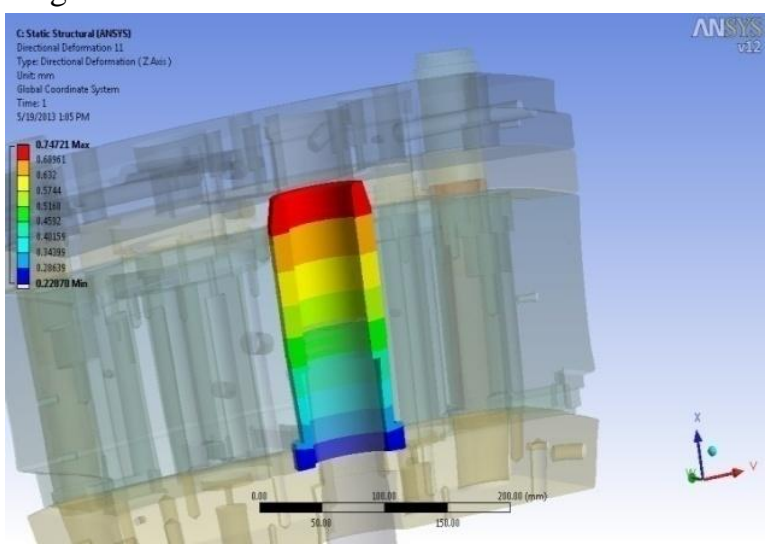

Fig. 3.24 Deformation along length of bush

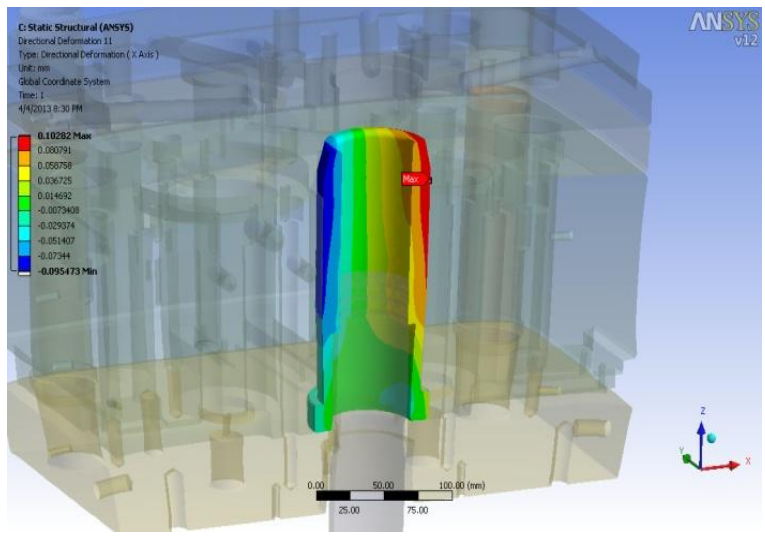

Fig. 3.25 Deformation along thickness of bush 


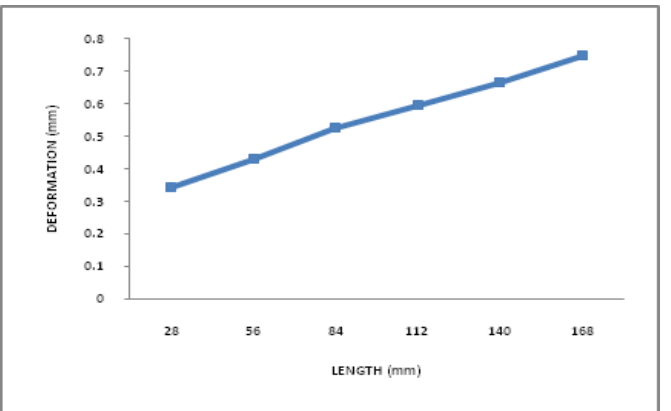

Fig 3.26 Deformation along length of bush

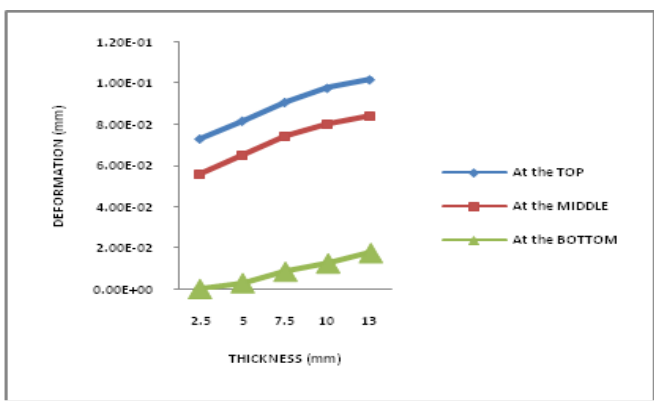

Fig. 3.27 Deformation along thickness of bush

From this result it is clear that deformation will be more at the top of bush than the bottom part. Because there is less transfer of heat at the bottom due to thermally constraint of cavity back plate. Corresponding stresses along the length and thickness of bush as shown in Fig.3.28. The Fig 3.30 and Fig 3.32 represent the corresponding graphs. Similarly the affect of strain along length and thickness is given in Fig 3.29 and corresponding graphs along the length and thickness of bush as shown in Fig 3.31 and Fig 3.33.

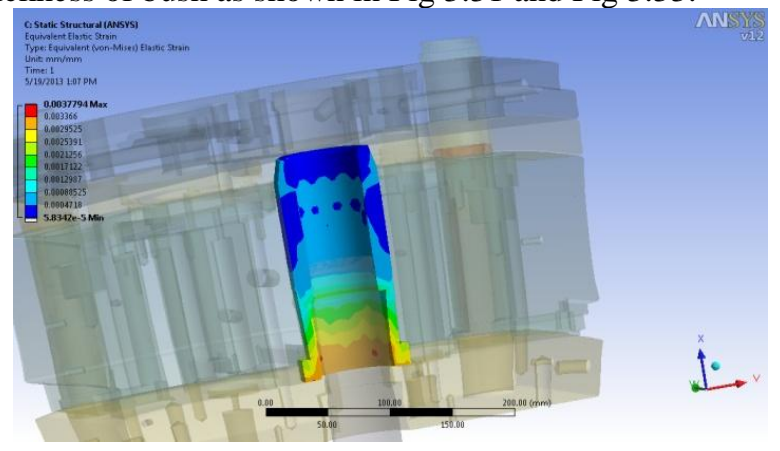

Fig 3.28 Stress in the bush

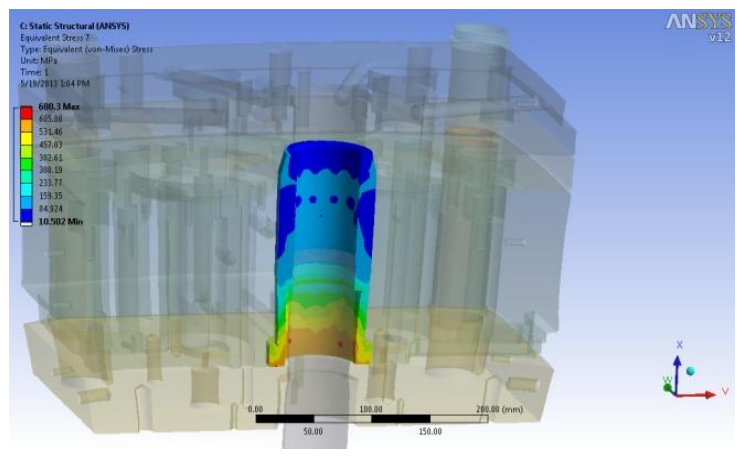

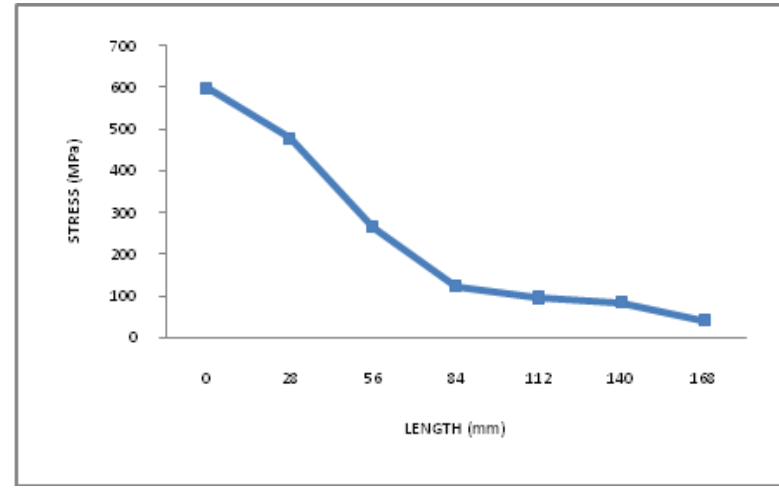

Fig 3.30 Stress along length of bush

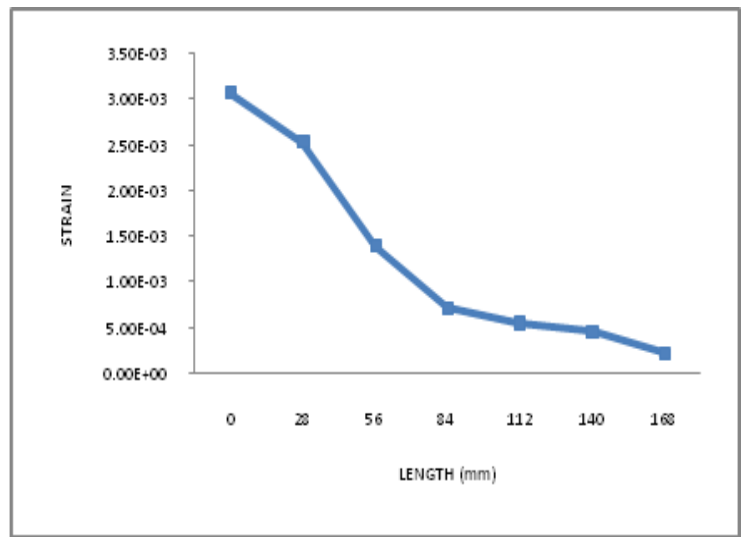

Fig 3.31 Strain along length of bush

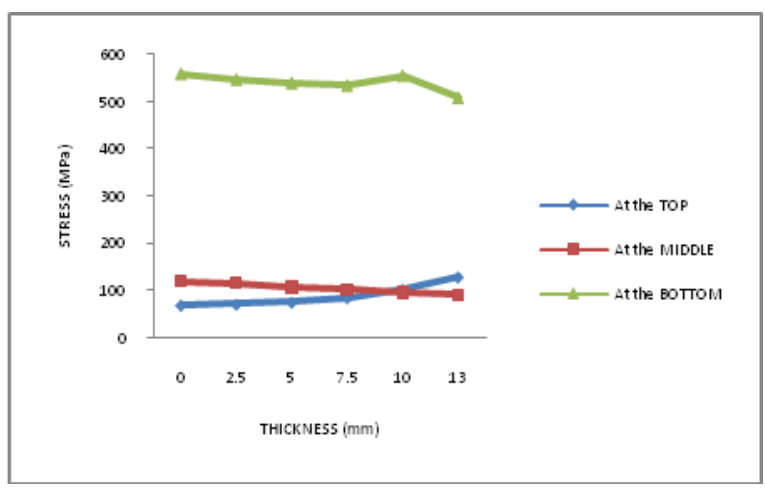

Fig 3.32 Stress along thickness of bush

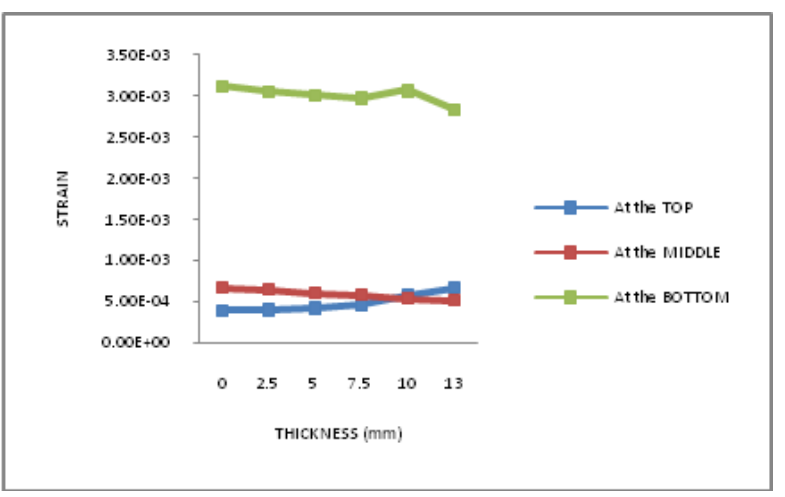

Fig 3.33 Strain along thickness of bush

Fig 3.29 Strain in the bush 


\section{Optimum clearance between plunger and bush}

Table 3.1 Plunger Diameter value

\begin{tabular}{|c|c|c|c|}
\hline & $\begin{array}{c}\text { Diameter } \\
\text { as per } \\
\text { drawing } \\
(\mathrm{mm})\end{array}$ & \multicolumn{2}{|c|}{ Diameter at $250^{\circ} \mathrm{c}(\mathrm{mm})$} \\
\hline PLUNGER & 51.98 & $\begin{array}{c}\text { Theoretical } \\
\text { Value }\end{array}$ & $\begin{array}{c}\text { FEM } \\
\text { Value }\end{array}$ \\
\cline { 3 - 4 } & 52.1296 & 52.1243 \\
\hline
\end{tabular}

Table 3.2 Bush Diameter value

\begin{tabular}{|c|c|c|c|}
\hline & $\begin{array}{c}\text { Diameter as } \\
\text { per drawing } \\
(\mathrm{mm})\end{array}$ & \multicolumn{2}{|c|}{ Diameter at $250^{\circ} \mathrm{c}(\mathrm{mm})$} \\
\hline BUSH & 52.01 & Theoretical Value & $\begin{array}{c}\text { FEM } \\
\text { Value }\end{array}$ \\
\cline { 3 - 4 } & & 52.1613 & 52.1491 \\
\hline
\end{tabular}

Table 3.1 and Table 3.2 give the comparison of diameter of plunger and bush respectively by theoretical and FEM values at $250^{\circ} \mathrm{c}$ tool temperature.

\section{CONCLUSION}

The thermal analysis of transfer molded tool has provided an understanding of thermal expansion and thermal stresses induced in the parts of the tool. From the result it is necessary to redesign of the transfer molded parts like cavity back plate, plunger and bush. The evaluated clearance between plunger and bush is more than the provided clearance that is by 0.0248 . Hence suggested to changing the plunger diameter that is by $51.955 \mathrm{~mm}$. suggested cavity back plate hole diameter is $56 \mathrm{~mm}$ in order to operate the plunger more precisely.

\section{REFERENCES}

1. P. Dumont a, L. Orge'as b, *, D. Favier b, P. Pizette c, C. Venet predicting Compression moulding of SMC: In situ experiments, modeling and simulation accepted march-2006, pp.352-368

2. Edward N. Peters, plastics: thermoplastics,thermosets, and elastomers.New York- 2002, pp.352-254

3. Li G. Bradshaw, Mar-Bal, Inc. Logan T. Eriksson, Mar-Bal, Inc.Steven W. Balogh, Mar-Bal, Inc. "Design of Experiment Study on Cure Reactivities of a BMC Material Effected by emperature, Levels of Peroxides and Inhibitors". St. Louis, MO USA October 18-20, 2006

4. S. H. Tang, Y. M. Kong, S. M. sapuan. Presented "design and thermal analysis of plastic injection mould". Malaysia - June 2005. 